\title{
LC-MS determination of L-DOPA concentration in the leaf and flower tissues of six faba bean (Vicia faba L.) lines with common and rare flower colors
}

\author{
Jinguo Hu ${ }^{1,3}$, Soon-Jae Kwon ${ }^{1,5}$, Jeong-Jin Park ${ }^{2}$, Erik Landry ${ }^{1,3}$, D. Scott Mattinson ${ }^{4}$, \\ and David R. Gang ${ }^{2}$
}

${ }^{1}$ USDA-ARS Western Regional Plant Introduction Station, 59 Johnson Hall, Washington State University, Pullman, WA 99164, USA; ${ }^{2}$ Institute of Biological Chemistry, Washington State University, Pullman, WA 99164, USA; ${ }^{3}$ Department of Crop and Soil Sciences, Washington State University, Pullman, WA 99164, USA; ${ }^{4}$ Department of Horticulture, Washington State University, Pullman, WA 99164, USA; ${ }^{5}$ Advanced Radiation Technology Institute, Korea Atomic Energy Research Institute, Jeongeup, Jeonbuk 580-185, Republic of Korea

Corresponding author: Jinguo Hu, USDA-ARS Western Regional Plant Introduction Station, 59 Johnson Hall, Washington State University, Pullman, WA 99164, USA.

Submission Date: June 19, 2015, Acceptance date: July 28, 2015: Publication date: July 31, 2015

\begin{abstract}
Background: Parkinson's disease (PD) is the second most common neurodegenerative disorder characterized by the loss of muscle control, which causes trembling of the limbs and head as well as impaired balance. L-DOPA (L-3,4-dihydroxy phenylalanine) is the major ingredient of several prescription drugs used to treat PD. Faba bean (Vicia faba L.) is one of the few plant species that is known to produce L-DOPA and has the potential to be developed as a functional food crop for people suffering with PD.
\end{abstract}

Objective: Aimed to provide needed information for people who want to use faba bean as a natural remedy or functional food to relieve PD symptoms, this study analyzed the variation of L-DOPA concentration in the leaf and flower tissues of six faba bean lines with common and rare flower colors.

Methods: Leaf and flower samples were taken from field grown plants with different flower colors, namely, pink with purple lines and black dots, pure white, brown, and crimson. Samples were freeze-dried and L-DOPA was quantified by a LC-MS system consisting of an ACQUITY UPLC in line with a Synapt G2 HDMS quadrupole time-of-flight mass spectrometer. This experiment was carried out in two consecutive years (2012 and 2013) and the plants used in the second year were grown from the seeds harvested from the plants used in the first year.

Results and Discussion: Our two-year study revealed a high level of variation in L-DOPA concentration for leaf and flower tissues among the six faba bean lines studied. The average L- 
DOPA concentration based on dry weight (DW) in flowers ranged from 27.8 to $63.5 \mathrm{mg} / \mathrm{g}$ and 18.2 to $48.7 \mathrm{mg} / \mathrm{g}$ for leaf tissues. There was no significant correlation between L-DOPA concentrations in flowers and leaves. The L-DOPA concentration in flowers and in leaves of the same line varied but was not statistically significant between the two years. Ideally, the genotype with the highest average L-DOPA concentration in both flowers and leaves would be grown as a natural source of this medicinally important molecule. When developing faba bean as a functional food crop for PD patients, a careful selection of genotype seems necessary for exploiting the full potential of this natural remedy.

Conclusions: Faba bean has the potential to be developed as a functional food crop for PD patients. Consumption of young pods and leaves is the most practical means for direct intake or processing of L-DOPA from the faba bean plant. Favorable environmental conditions for growth will optimize L-DOPA yield. Further analysis of the genetic control of L-DOPA synthesis and metabolism will be valuable, with the possibility of developing environmentally resilient cultivars that can produce desirable amounts of L-DOPA for pharmaceutical use.

Key words: Faba bean, L-DOPA, Parkinson's disease

\section{INTRODUCTION}

Parkinson's disease (PD) is named after English Doctor James Parkinson who first identified the condition in 1817 [1]. Today, PD is considered as the second most common neurodegenerative disorder affecting approximately $1 \%$ of the human population above the age of 65 [2]. The main symptoms of Parkinson's disease include tremor, slowness of movement and muscle stiffness or rigidity [1]. These symptoms are caused by an insufficient amount of dopamine, a monoamine neurotransmitter in the striatum [3], due to the death of dopaminergic neuron cells in the substantia nigra [1]. Recent studies revealed that neuron death in the brains of PD patients could be linked to genetic mutation causing abnormal handling of misfolded proteins, increased oxidative stress, mitochondrial dysfunction [4] and inflammation [5]. Collectively, all of these conditions could lead to a new avenue of PD therapy in the future. Meanwhile, administration of levodopa, the dopamine precursor, remains the most popular and effective treatment for PD [6].

Levodopa is the International Nonproprietary Name of the chemical L-DOPA (L-3, 4dihydroxy phenylalanine), which is a metabolite with diverse biological functions in humans, animals and some plants. In humans, L-DOPA can cross the blood-brain barrier and be converted to dopamine in the brain. Chemically synthesized L-DOPA is the major ingredient of several prescription drugs used in the therapy of dopamine replacement for PD patients. Although administration of L-DOPA can effectively alleviate the symptoms associated with impaired motor functions and greatly improve the quality of the life of patients with PD, it is compromised by certain serious side effects such as L-DOPA-induced dyskinesia [7]. Alternative sources of LDOPA have been sought to treat PD. Several research publications [8-11] and a few anecdotal testimonies $[12,13]$ have documented the beneficial effects of consuming faba bean or fava bean (Vicia faba L.) seedlings and pods. These reports stimulated interest in using faba bean to improve the quality of life for PD patients. Earlier studies sought various ways to enhance the 
effectiveness of fava bean sprouts as a treatment for the symptoms of Parkinson's disease [1416] (Randhir at al., 2002; Shetty et al., 2003; Randhir and Shetty 2004). This paper reports the variation of L-DOPA concentration in the leaf and flower tissues of six faba bean lines with common and rare flower colors to provide needed information for people who want to use faba bean as a natural remedy or functional food to relieve PD symptoms.

\section{MATERIALS AND METHODS}

Used in the current study are six entries including two white flowered NPGS (National Plant Germplasm System) accessions maintained in Pullman, WA, two commercial cultivars with brown and crimson colored flowers, and two breeding lines resulting from a cross between Extra Precoce Violetto, a vegetable type cultivar and Hiverna/2-5EP1, a winter-hardy breeding line from Germany (Table 1).

Table 1. Information on the six entries used for L-DOPA analysis

\begin{tabular}{lll}
\hline Name & Flower color & Origin \\
\hline Oakland purple & Brown & Purchased by mail order in 2010 \\
P01-A1 & $\begin{array}{l}\text { Pink with purple vein and } \\
\text { black dot }\end{array}$ & Extra Precoce Violetto x Hiverna/2-5EP1 F 4 \\
Triple Blanche & Pure white & NPGS PI 433537 acquired from Canada \\
P01-A2 & $\begin{array}{l}\text { Pink with purple vein and } \\
\text { black dot }\end{array}$ & Extra Precoce Violetto x Hiverna/2-5EP1 F 4 \\
Crimson Flower & Crimson & Purchased by mail order in 2010 \\
Maris Bead & Pure white & NPGS PI 655345 acquired from New Zealand \\
\hline
\end{tabular}

Seeds were directly seeded in the field during April of 2012 and 2013. At flowering time, three leaflet and three flower bud samples were taken from three plants of each entry. In 2012, the plants were grown at Washington State University's Central Ferry Research Farm in Central Ferry, WA (46 $39^{\prime} 5.1^{\prime \prime}$ N- $\left.117^{\circ} 45^{\prime} 45.4^{\prime \prime} \mathrm{W}\right)$. Each plant sampled was marked with an ID tag for harvesting seeds for the second year experiment. In 2013, the plants were grown at WSU's Whitlow Farm in Pullman, WA (4644'3.2”N-117'7'25.8”W). All samples were freeze-dried with a VirTis Bench Top Lyophilizer (SP Scientific, Stone Ridge, NY) and stored in a $-20^{\circ} \mathrm{C}$ Freezer until L-DOPA extraction and analysis.

The extraction of L-DOPA followed the procedure of Shetty et al. [17], with some modifications. The dried leaf and flower tissues were ground into fine powder with a TissueLyser II (Qiagen, Valencia, CA) at a frequency of $30 \mathrm{~Hz}$ for $30 \mathrm{sec}$. Approximately 100 $\mathrm{mg}$ of the powder was taken for L-DOPA extraction with $1 \mathrm{ml}$ acetate buffer $\mathrm{pH} 4.2$ containing, $0.215 \mathrm{mM}$ octyl sulfate, and $0.074 \mathrm{mM}$ NaEDTA. Each sample was filtered through $0.45-\mu \mathrm{m}$ cellulose acetate filter (Restek, Corp., Bellefonte, PA) before quantification.

L-DOPA was quantified by an ACQUITY UPLC system with a HSS T3 column (Waters, Milford, MA). MS (Mass Spectrometric) analysis was performed on an inline Synapt G2 HDMS time-of-flight mass spectrometer (Waters, Milford, MA). Chromatographic separation and 
quantification was carried out with the following LC conditions: Column: Waters UPLC HSS T3

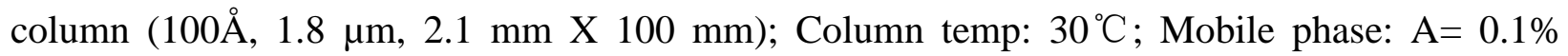
formic acid (FA), $5 \mathrm{mM}$ ammonium phosphate (in water), $\mathrm{B}=$ acetonitrile (0.1\% FA); Flow rate: $0.30 \mathrm{~mL} \cdot \mathrm{min}^{-1}$; Injection volume: $2 \mu \mathrm{L}$; and Gradient: initial $97 \% \mathrm{~A}$ and $3 \% \mathrm{~B}$, linear gradient to $80 \% \mathrm{~A}$ and $20 \% \mathrm{~B}$ at $6 \mathrm{~min}$, linear gradient from $6.2 \mathrm{~min}$ to $8 \mathrm{~min}$ to $2 \% \mathrm{~A}$ and $98 \% \mathrm{~B}$, linear gradient from 8.2 to $11 \mathrm{~min}$ to $97 \%$ A and 3\% B. In 2012, L-DOPA (Sigma-Aldrich, St Louis, MO) standards were made with acetate buffer in a series: 50, 100, 200 and $300 \mathrm{mg} \cdot \mathrm{ml}^{-1}$. The correlation between the peak area (y) and the L-DOPA mass in $\mathrm{ng}(\mathrm{x})$ was high $\left(r^{2}=0.9981\right)$ and described by the equation: $y=1346.8 x$. In 2013, the series of concentration standards for LDOPA were $2,10,50,100,200$ and $500 \mathrm{mg} \cdot \mathrm{ml}^{-1}$ and were run under the same conditions. The correlation was $r^{2}=0.9988$ and $\mathrm{y}=1012.2 \mathrm{x}$. All samples were chromatographed under the same conditions as the standards and the concentration was calculated at $\mathrm{mg} \cdot \mathrm{g}^{-1} \mathrm{DW}$ (dry weight) in leaf and flower buds.

\section{RESULTS AND DISCUSSION}

In 2012, we sampled leaf and flower bud tissues from a total of 18 plants (three plants of each of the six entries). Very little variation of L-DOPA concentration was observed in both flower and leaf tissues within an accession. However, the difference between the six accessions was highly significant ( $p=0.002$ for flower buds and $p=0.001$ for leaf samples). The average L-DOPA concentration in flowers ranged from 27.8 to $63.5 \mathrm{mg} \cdot \mathrm{g}^{-1} \mathrm{DW}$ and that in leaf tissues ranged from 18.2 to $48.7 \mathrm{mg} \cdot \mathrm{g}^{-1} \mathrm{DW}$. It is worthwhile to mention that there was no significant correlation between L-DOPA concentrations in flower buds and leaves $(\mathrm{r}=0.253)$. The accession with crimson colored flowers had the highest L-DOPA concentration $\left(63.5 \mathrm{mg} \cdot \mathrm{g}^{-1}\right)$ in flowers but low levels $\left(20.5 \mathrm{mg} \cdot \mathrm{g}^{-1}\right)$ in leaves. The accession with brown-colored flowers had high LDOPA concentrations in both flowers $\left(55.7 \mathrm{mg} \cdot \mathrm{g}^{-1}\right)$ and leaves $\left(48.7 \mathrm{mg} \cdot \mathrm{g}^{-1}\right)$. It also seemed that L-DOPA concentration was independent from flower color. The three entries that had high LDOPA content had a different flower color of white $\left(55.0 \mathrm{mg} \cdot \mathrm{g}^{-1}\right)$, crimson, or brown.

In 2013, seeds harvested from the 18 plants tested in 2012 were planted in single row plots and leaf and flower bud tissues were sampled from three plants in each plot. Although a larger range of L-DOPA concentration within an entry was observed for both leaf and flower tissue, the difference among the six entries was still statistically significant $(p=0.0231$ for flower buds and $p=0.0046$ for leaf samples). The average L-DOPA concentration in flowers ranged from 34.3 to $64.2 \mathrm{mg} \cdot \mathrm{g}^{-1} \mathrm{DW}$ and that in leaf tissues ranged from 20.5 to $48.4 \mathrm{mg} \cdot \mathrm{g}^{-1} \mathrm{DW}$. Year $/ \mathrm{site}$ was not a significant source of variation when analyzed with a two-sample t-test assuming equal variances: the values of $\mathrm{P}(\mathrm{T}<=t)$ two-tail was 0.709 and 0.415 , for flower and leaf, respectively. Similar to the observation in the previous year, there was no significant correlation between L-DOPA concentrations in flower buds and in leaf tissues $(\mathrm{r}=0.202)$.

The two years of data (Figure 1) indicated that L-DOPA concentration in flowers is more stable than that in the leaves from year to year. The correlation of L-DOPA concentration in flowers in the six entries observed in 2012 and 2013 is high and approaching the statistically significant level ( $\mathrm{r}=0.799$ and $p=0.056)$. While the correlation of L-DOPA concentration in leaf in the two years was negligible at $r=0.046$. There was no significant correlation between L- 
DOPA concentration in flower bud and in leaf of the same entry as $r$ varied from 0.202 (2013), 0.253 (2012) and 0.188 (average over both years). This observed variation implies that the genetic control of L-DOPA concentration is of the typical nature for quantitative traits in plants, underlying genetic complexity from multiple interacting genes and being influenced by the environmental conditions.
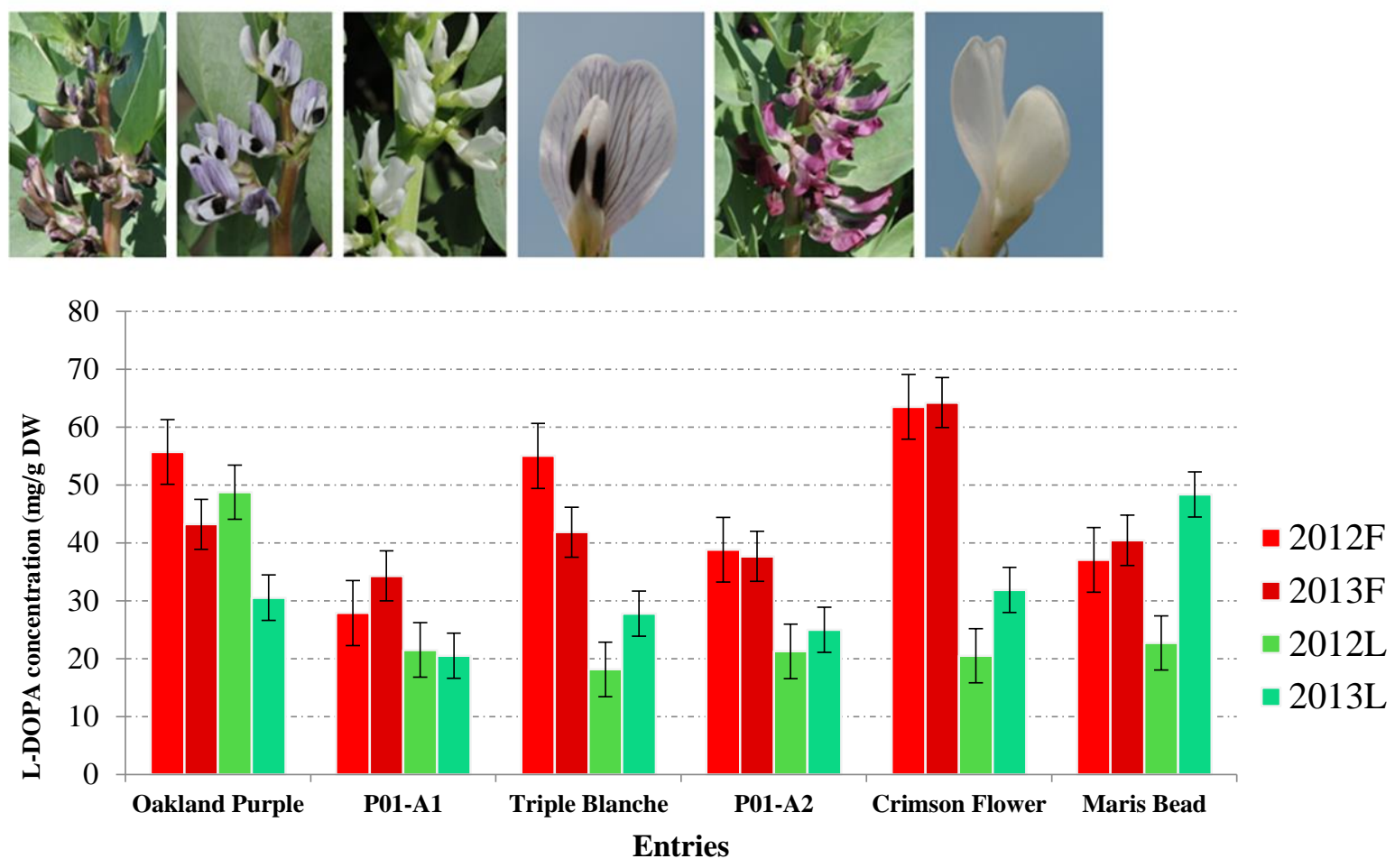

Figure 1. Results of UPLC analysis of L-DOPA concentration variation in flower (red) and leaf (green) tissues of six entries grown in two consecutive years. In 2012, samples were taken from three plants per entry and in 2013 from nine plants per entry. The top panel shows the flower color of the six faba bean entries.

L-DOPA was first isolated from faba bean over 100 year ago [18]. After L-DOPA was used to treat Parkinson's disease in the 1970s, researchers examined the distribution of L-DOPA in different plant parts and the metabolic changes during development. These findings determined that L-DOPA is present in several tissues of faba bean [19], with 9-day old seedlings containing $2 \%$ [20] and young pod material containing $6 \%$ and $6.75 \%$ of L-DOPA [21], while young developing seeds contain approximately $4 \%$ of L-DOPA decreasing to less than $1 \%$ at seed maturity [22]. Geng [23] reported that there is substantial variation in L-DOPA content among six organs of the faba bean cultivar 'Qinghai 166': flower, 6.52\%; leaf, 5.74\%; stem, 1. 99\%; pod, $0.03 \%$; seeds, $0.03 \%$; seed coat, $0.025 \%$. Further, Cao [24] reported the L-DOPA content of multiple faba bean cultivars: flowers from $3.99 \%$ to $10.18 \%$ DW across 197 cultivars; seedlings from $4.39 \%$ to $7.64 \%$ DW across 32 cultivars; seeds from $0.034 \%$ to $0.095 \%$ DW across 52 cultivars with green seed coat. The current study analyzed the L-DOPA content in the flower and 
leaf tissues of six entries with common and rare flower colors and found substantial variation of L-DOPA content which appears to be attributed to both genetic and environmental influence.

Faba bean is one of a few plant species that have the potential to be used as a natural source of L-DOPA. Over the years, researchers have gained important knowledge on L-DOPA via the faba bean crop. The following three aspects are highly relevant to using faba bean for PD patients: 1) there is significant variation in L-DOPA concentration among different cultivars or varieties, 2) the distribution of L-DOPA is uneven in various parts (tissues) and varies with developmental stage, and 3) certain adverse growing conditions such as drought also affect the L-DOPA concentration in the plant [22]. Therefore, in order to attain a satisfactory result in using faba bean for alleviating PD symptoms, the first consideration is to choose an appropriate cultivar with adequate L-DOPA content. As a worldwide-grown cool season legume crop, faba bean has relatively rich genetic resources that remain unexplored for L-DOPA content. There are over 43,500 faba bean accessions conserved in 37 national or international genebanks [25]. The second consideration is to use the tissue or organ that contains adequate amounts of L-DOPA to alleviate PD symptoms. The mature dry faba bean seeds may be nutritious but only contain a fraction of the L-DOPA present within young pods, immature bean seeds, flower buds or green leaf tissue.

Conclusions: Faba bean has the potential to be developed as a functional food crop for PD patients. Consumption of young pods and leaves is the most practical means for direct intake or processing of L-DOPA from the faba bean plant. Favorable environmental conditions for growth will optimize L-DOPA yield [26]. Further analysis of the genetic control of L-DOPA synthesis and metabolism will be valuable, with the possibility of developing environmentally resilient cultivars that can produce desirable amounts of L-DOPA for pharmaceutical use.

List of abbreviations: UPLC: Ultra performance liquid chromatography; MS: mass spectrometry; L-DOPA: L-3, 4-dihydroxy phenylalanine; PD: Parkinson's disease; DW: dry weight

Competing Interests: The authors have no financial interests or conflicts of interest.

Authors' Contributions: All authors contributed to this study.

Acknowledgements and Funding: The authors would like to thank funding from USDA ARS CRIS Project 5348-21000-026-00D and USDA NIFA Multistate Research Project W-006.

\section{REFERENCES}

1. Jankovic J. Parkinson's disease: clinical features and diagnosis. Journal of Neurology, Neurosurgery \& Psychiatry 2008; 79(4):368-376.

2. de Lau LM, Breteler MM. Epidemiology of Parkinson's disease. The Lancet Neurology 2006; 5(6):525-535. 
3. Ehringer H \& Hornykiewicz, O. Distribution of noradrenaline and dopamine (3hydroxytyramine) in the human brain and their behavior in diseases of the extrapyramidal system. Klinische Wochenschrift 1960; 38:1236.

4. Exner N, Lutz AK, Haass C, Winklhofer KF. Mitochondrial dysfunction in Parkinson's disease: molecular mechanisms and pathophysiological consequences. The EMBO journal 2012; 31:3038-3062.

5. Niranjan R. The role of inflammatory and oxidative stress mechanisms in the pathogenesis of Parkinson's disease: focus on astrocytes. Molecular neurobiology 2014; 49:28-38.

6. Brichta L, Greengard P, Flajolet M. Advances in the pharmacological treatment of Parkinson's disease: targeting neurotransmitter systems. Trends in neurosciences 2013; 36(9):543-554.

7. Fox, SH \& Brotchie JM (Ed): Levodopa-induced dyskinesia in Parkinson's disease. Springer London 2014.

8. Rabey JM, Vered Y, Shabtai H, Graff E, Korczyn AD. Improvement of parkinsonian features correlate with high plasma levodopa values after broad bean (Vicia faba) consumption, J Neurol Neurosurg Psychiatry 1992; 55(8):725-727.

9. Kempster PA, Bogetic Z, Secombei JW, Martin HD, Balazs NDH, Wahlqvist ML. Motor effects of broad beans (Vicia faba) in Parkinson's disease: Single Dose Studies. Asia Pac J Clin Nutr 1993; 2:85-89.

10. Rabey JM, Vered Y, Shahtai H, Graff E, Harsat A, Korezyn AD. Broad bean (Vicia faba) consumption and Parkinson's disease. Adv Neurol 1993; 60:681-684.

11. Apaydin H, Ertan S, Ozekmekci S. Broad bean (Vicia faba)--a natural source of L-dopa-prolongs "on" periods in patients with Parkinson's disease who have "on-off" fluctuations, Mov Disord 2000; 15(1):164-166.

12. Anonymous. Fava Beans and Dopamine. [http://www.favabeans.parkinsonsrecovery.com/category/fava-beans-and-dopamine] Accessed on 30 April, 2015.

13. Holden K. Fava Beans, Levodopa, and Parkinson's disease. [http://www.scienzavegetariana.it/nutrizione/favabeans.html] Accessed on 30 April, 2015.

14. Randhir R, Shetty P, Shetty K. L-DOPA and total phenolic stimulation in dark germinated fava bean in response to peptide and phytochemical elicitors. Process Biochemistry 2002; 37(11), 1247-1256.

15. Shetty P. Atallah MT, Shetty K. Stimulation of total phenolics, L-DOPA and antioxidant activity through proline-linked pentose phosphate pathway in response to proline and its analogue in germinating fava beans (Vicia faba). Process Biochemistry 2003; 38(12):17071717.

16. Randhir R. \& Shetty K. Microwave-induced stimulation of L-DOPA, phenolics and antioxidant activity in fava bean (Vicia faba) for Parkinson's diet. Process Biochemistry 2004; 39(11):1775-1784.

17. Shetty P, Atallah MT, Shetty K. Effects of UV treatment on the proline-linked pentose phosphate pathway for phenolics and L-DOPA synthesis in dark germinated Vicia faba. Process Biochemistry 2002; 37(11):1285-1295. 
18. Guggenheim M. Dioxyphenylalanine, a new amino acid from Vicia faba. Z Physiol Chem 1913; 88:276.

19. Longo R, Castellani A, Sberze P, Tibolla M. Distribution of L-DOPA and related amino acid in Vicia. Phytochem 1974; 13:167-171.

20. Goyoaga C, Burbano C, Cuadrado C, Varela A, Guillamón E, Pedrosa MM, Muzquiz M. Content and distribution of vicine, convicine and L-DOPA during germination and seedling growth of two Vicia faba L. varieties. European Food Research and Technology 2008; 227(5):1537-1542.

21. Burbano C, Cuadrado C, Muzquiz M, \& Cubero JI. Variation of favism-inducing factors (vicine, convicine and L-DOPA) during pod development in Vicia faba L. Plant Foods for Human Nutrition 1995; 47(3):265-274.

22. Hill-Cottingham DG, \& Purves JV. Changes during development in the free amino acid constituents of fababean (Vicia faba L.) plants. Plant and soil 1983; 75(3):435-442.

23. Geng, G. Analysis of L-DOPA Contents in six organs of a faba bean cultivar. Northern Horticulture 2012; 2:26-27.

24. Cao Y. Study on L-DOPA content of Vicia faba L. PhD thesis. Fujian Agriculture and Forestry University, Fuzhou, China. 2010. (in Chinese with English abstract)

25. Duc G, Bao SY, Baum M, Redden B, Sadiki M, Suso MJ, Vishniakova M, Zong XX. Diversity maintenance and use of Vicia faba L. genetic resources. Field Crops Res 2010; 115:270-278.

26. Landry E, Coyne C, Hu J. Agronomic performance of spring-sown faba bean in southeastern Washington. Agron J 2015; 107(2):574-578. 